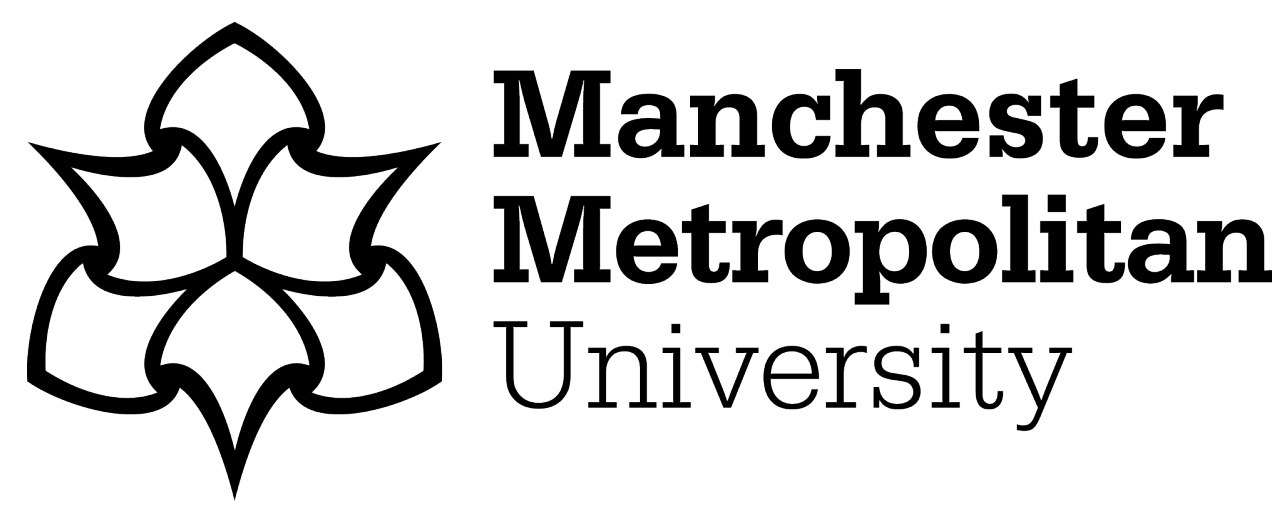

Daniels, JE ORCID logoORCID: https://orcid.org/0000-0002-9328-5986, Bell, Barbara ORCID logoORCID: https://orcid.org/0000-0001-6436-2041 and Horrocks, Christine (2018) Capturing the realities of sports programmes: systematic 'messiness'? International Journal of Sport Policy and Politics, 10 (4). pp. 779-794. ISSN 1940-6940

Downloaded from: https://e-space.mmu.ac.uk/617464/

Version: Accepted Version

Publisher: Taylor \& Francis (Routledge)

DOI: https://doi.org/10.1080/19406940.2018.1513414

Please cite the published version 


\title{
Capturing the realities of sports programmes: systematic 'messiness'?
}

\author{
John E Daniels, Barbara Bell and Christine Horrocks \\ Department of Sport and Exercise Sciences, The Manchester Metropolitan University, Manchester, UK
}

\begin{abstract}
There is growing pressure for those who work in community sport to design and deliver sports programmes with evaluation in mind. Beyond reporting on how interventions have been implemented, those managing interventions need to be able to fully explain not just what works but why it works. This paper will demonstrate the application of Realistic Evaluation through a repertoire of concepts and methods. The intervention strategy and evaluation were developed by a sub-regional Community Sport Network involving research expertise from the local university, the public sector sport development department and third sector sports clubs, supported by Sport England's Community Investment Fund. The paper will present 'outcome patterns' for the strategy and explain the methods that helped build them, developed through a phased and longitudinal evaluation design. Using contextmechanism-outcome configurations long-term outcomes such as improvements to health and wellbeing were related to the necessary conditions and most appropriate mechanisms in the selected programmes. Recommendations are based on the reflections of evaluating this sport and physical activity strategy in the Northwest of England. This will contribute to developing insight for evaluation approaches for multiple sports projects within a community setting.
\end{abstract}

ARTICLE HISTORY

Received 5 December 2017 Accepted 27 July 2018

\section{KEYWORDS}

Realist evaluation; community sport; programme evaluations; evidence-based

\section{Introduction}

The central tenet of current evaluation theorists and practitioners is that evaluation should facilitate change. Significantly, sport policy is following suit and there is now a greater emphasis of change being based on '....insight and evidence of what works' (Department for Digital Media Culture and Sport [DDCMS] 2015, p. 22). The emergence of the 'what works' discourse in Health and Education (Davies 2000) has meant evaluation practices in sport have become more theory driven (Weiss 1998). This allows for a greater focus on progress and process as opposed to the more traditional notion of 'end-game' evaluation (Rossi et al. 2004). In sport development literature, Nichols (2005), Coalter (2007) and Bell (2010) drew attention to not just 'what works' but why it works and for whom it works best. If in the past, evaluation was an intervention afterthought, current practice is realising the potential of learning from process and delivery. Consequently, evaluation research has become multi-dimensional. This may add to the complexity of evaluation but it also gives the evaluator richer information and, according to Clarke and Dawson (1999), gives greater sensitivity to complex and dynamic social arenas - such as those recently targeted in UK 
sports policy. Examples for sport include work by Nichols (2001) and his application of scientific realism to explain outcomes patterns for sport and crime reduction programmes.

More recently, Chen and Henry (2016) used realist evaluation approaches to explain participation legacy impact on non-hosting regions of the 2012 Olympics and Paralympic Games. This expanding evidence and insight is adding to the academic credibility of sport policy by challenging knowledge and improving understanding of issues that determine the value and impact of sport programmes. This includes activity for the development of sport (Bell 2004, Green and Houlihan 2004, Grix and Carmichael 2012) and development through sport programmes that target broader social issues such as health (Reddy et al. 2017), crime (Krustrup et al. 2016) and urban regeneration (Davies 2016).

There has been a response to what has been termed a '...lack of evidence discourse' (Adams and Harris 2014, p. 140) and critiques of the limited rigour of studies concerned with the impact of sport programmes (Coalter 2007, 2013). Collins and Kay (2003, p. 248) alerted academia to '... descriptive, atheoretical, short term, output related' evaluations that lacked context. Thus, evaluations of sports programmes were not demonstrating the principles of rigour demanded to underline the requirements of government policy. More recently, despite significant investments since 2002, sport policy makers referred to a need to develop a '...robust understanding of how sport contributes [to outcomes] to ensure a basis for how impact is measured for the future (DDCMS 2015, p. 73)'.

The debate continues about what constitutes good practice in evaluations of sport development activity (Harris and Adams 2016, Weed 2016, Coalter 2017). For example, the academic community continue to question sport's pervasive links with broader social agenda such as improvements to physical health (Weed 2016). With increasing pressures on budgets, particularly for community sport (Widdop et al. 2017) and having been challenged by successive governments to improve the evidence base in the UK, both community sport and the research community are under increased scrutiny to justify the assumptions supporting development through sport (Houlihan and White 2002). Thus, this paper presents a 'Realistic evaluation' approach to a Local Authority-based Sport and Physical Activity strategy, researched over a 6-year period. This included selected community sport programmes, namely a coach mentoring programme, a community sports volunteering programme and a disability sports programme.

The paper begins by setting out the complexities of Realistic Evaluation as a methodological approach, underpinned by a realist ontology and interpretivist epistemology. The findings for the Realistic Evaluation as an evidence base at a strategic level for community sport development are then explored. Finally, the paper reflects on the Realistic Evaluation process, acknowledges limitations and challenges and make suggestions for future evaluation research in the development of community sport.

\section{Realistic evaluation and community sport programmes}

There have been several attempts to develop theory-based evaluation protocols in sport. For example, Bean et al. (2015, p. 39) participatory and utilisation focussed evaluation of a women's sports and physical activity programme. Reflections on the evaluation process concluded that such approaches are successful providing that the evaluation is seen as '....a natural process in program development and implementation'. Hart et al. (2009) also emphasised that evaluation had to be perceived as something that was done with a programme rather than done to it. They rationalised this approach by embracing Weiss' (1972) philosophy that participatory research is theory based, as it would attempt to explain how and why programmes might work as well as attempting to understand the stakeholder values and context. Further, participatory evaluation acts to enhance stakeholder relationships due to the constant collaboration. Finally, that collaboration between the stakeholders would improve capacity for experiential learning and sharing of knowledge through all levels of representation allowing improved policy coherence (Frisby et al. 2004). 
While this approach has its strengths, there is a danger of casting the net too widely in terms of stakeholder participation and the evaluation exercise could become far too resource intensive. This is particularly salient where there is a range of stakeholders representing very different communities. Time and effort needs to be taken to provide ways through which seldom heard groups can be involved as far as possible (Sixsmith and Daniels 2011). Additionally, this approach assumes that stakeholders are capable of building knowledge and have the experience required to inform choice. Pawson and Tilley (1997) and O'Sullivan and D'Agostino (2002) suggested that the evaluator's role should be to organise theoretical frameworks and empirical evidence as a prerequisite for participatory, theory-based evaluation. Politically, there could also be problems with stakeholder consensus and the inevitable time constraints this could place on the programme (Mercier 1997).

Pawson and Tilley's (1997) Realistic Evaluation epistemological position is that '...it is not programmes that "work", but the generative mechanisms that they release by way of providing reasons and resources to change behaviour' (1997, p. 79). This process is termed generative causality. Rather than a programme having an impact on a person, a Realistic Evaluation tries to illuminate the relationship between the participant, the programme mechanisms and the context in which they interact (or between structure and agency). The ontological position of Realistic Evaluation is based on Bhaskar's (1975) critical realism philosophy. That is, the world must be understood at different human levels of nature that look beyond biology or physics and focus on human activity. Pawson and Tilley (1997) explain that social reality is stratified and different social actors will perceive their own situations and circumstances differently. Consequently, Realistic Evaluation challenges the evaluator to understand the social world as perceived by the programme participants and includes their view of the programme, embedded in their individual level of social reality.

The logic behind Realistic Evaluation is that social enquiry should act to explain significant regularities $(\mathrm{R})$ or outcomes $(\mathrm{O})$ such as changes in participation for sport in deprived, urban areas or changes in the communities that can be explained as a consequence of interventions using sport. Explanation may take the form of proposing some underlying mechanisms (M). For example, a 'door-step' sport intervention may reduce barriers to sport by providing sport activities (the mechanism) for free. The outcome $(\mathrm{O})$ may take the form of observable improvements in wellbeing and community cohesion, as youth engage in the sport programme regularly over time. Pawson and Tilley (1997) suggested that evaluation should delineate theories of how that mechanism works. For example, new participants have exposure to a greater network to improve social capital through sport and have been able to adopt a more active lifestyle with measurable effects on health indicators. These explanations generate the new regularity $(\mathrm{R})$ or outcome $(\mathrm{O})$ explaining the relationship between how it was achieved.

Importantly, this framework acknowledges the conditions or contexts (C) for the outcomes. Contexts describe the circumstances that trigger the mechanism and generate outcomes. For example, increases in participation and social cohesion may only be observable if the community have the capacity and ability to take greater control of the door-step sport programmes and are supported by enthusiastic and well-qualified sport development officers. Using this approach, the relationship between sport and social cohesion can be explained but only in specific circumstances. In this paper, this logic will be referred to through context-mechanism-outcome (CMO) configurations. The idea is to determine: '...which individuals, subgroups and locations might benefit most readily from the programme, and which social and cultural resources are necessary to sustain the changes' (Pawson and Tilley 1997, p. 85).

This explanation is significant in evaluation research as it allows for the identification of relevant questions and appropriate methodological choices. As context shifts or changes so too will the relevant theories or explanations, and also the appropriateness of the questions at a given point in time. Arguably, more method-driven evaluations would not accommodate for changes in context that are so apparent in the lifespan of a local community sport and physical activity strategy. Nichols' (2005) application of this to sport and youth crime highlighted how difficult it is to 
measure when the outcomes are sufficient to support (or refute) the hypothesised position or demonstrate significant change. Herein lies the issue of the politics of evidence, particularly in sport where novel approaches may be applied to tackle problems. While Nichols was supportive of scientific realism's capacity to capture the structure-agency relationship, how this knowledge defused into policy change remained a contested issue. Similarly, Harris (2018) noted the capacity for sport for development programmes to apply a realist evaluation to programmes. There was acknowledgement that adopting such an approach '...fostered a greater learning of how the practitioners see their projects working' (Harris 2018, p. 18) but also raised questions about how practitioners could and should evaluate programmes and the importance of supporting networks to facilitate the evaluation process. Unlike mainstream government departments such as Health and Education, practitioners of development through sport programmes have only relatively recently been challenged to demonstrate evidence-based practice.

\section{The importance of the setting for the evaluation of community sport}

As a consequence of the Game Plan review in 2002, in the UK, national, regional and local strategies required local stakeholders or actors for sport and physical activity to produce a working strategic document in order to promote a shared vision and framework from which all parties were able to work (Audit Commission 2002). The Local Authority in this paper recognised that no one agency should be responsible for the development and delivery of community sport and physical activity objectives thus, established a network of stakeholders across different sectors. This Community Sport Network (CSN) was typical of the 'single system' approach recommended by Sport England (Hylton and Bramham 2008, p. 36). At a very basic level, these groups aligned their aims to Sport England's policy at the time to:

raise participation in sport and physical activity (1\% per annum), widen access to opportunities in sport and physical activity, and promote wider social benefits of sport and physical activity.

This research was situated in a single Local Authority in North West of England. Within the Local Borough Council, there are two jurisdictions with a combined population of 370,127 residents (Office for National Statistics 2011). One area is a post-industrial 'new-town' developed in the middle of the nineteenth century, although the economic base had diversified greatly in the last 20 years or so, with some upturn in local employment conditions away from traditional industries. The other area is a historic market town and is an important service centre to an attractive rural area where the dairy industry and tourism are particularly important. Overall, the Borough is a prosperous one. In recent years, despite an economic downturn, there have been major developments for new homes and a rapid increase in jobs and investment. Despite this, there are areas where residents' quality of life is lower than for residents elsewhere in the Borough, with 11 areas within the top 20\% of most deprived areas in England (Ministry of Housing, Communities and Local Government 2015).

Sport England's 'Active People Survey 1' (2006a) reported that almost one in five (17.2\%) of adults in the Borough participated in at least $30 \mathrm{~min}$, moderate intensity sport and active recreation (including recreational walking) on three or more days of the week. This is lower than the average rate reported (Sport England 2006a) for the County (20.1\%) and placed the Borough in the lowest 25th percentile across all Local Authorities for England. The Community Investment Fund was designed to support these 'hard to reach' communities and use sport and physical activity to improve their lives. The published Sport and Physical Activity strategy, its network of stakeholders and its collection of programmes were set in place to:

improve health and wellbeing, enhance the sporting infrastructure, develop education and skills, and create safer and stronger communities. 


\section{Towards an evaluation methodology}

A Realistic Evaluation perspective treats programmes not as targeted social systems but as an embedded and integrated social construct where the interplay of stakeholders, location, history and future prospects are key to explaining less about if the programme worked but what it was about the programme that may best explain why it worked. In taking a realistic epistemology, this research developed outcome patterns based on the 'CMO' model offered by Pawson and Tilley (1997) and consequently covered several contingent contexts and different reflective participants (Pawson and Tilley 1997). These outcome patterns designate the broad, generative mechanisms that operate in the real world from programme implementation to the strategic outcomes.

Embedding a Realistic Evaluation philosophy during the initial stages of developing the Sport and Physical Activity Strategy was essential to understanding this realist approach. Programme leaders were aware of the intentions to map strategic outcomes to mechanisms and context. The programme leaders were also very much aware of the researcher's 'facilitatory role' in this process. This 'participatory' effort, in part, allowed the evaluation to transcend from its more traditional programme level application to a higher, strategic level. Thus, each programme leader was made fully aware of their input and the strategy outcomes their respective programmes were aligned to. This shared learning and interaction between the researcher and the stakeholder groups happened both as a consequence of the research process and as a result of the embedded role of the researcher in the CSN. Consequently, the evaluation was part of the CSN's meeting agenda. This meant that the research took such opportunities to disseminate information on progress and allow the various stakeholders to learn from each other over the research period.

\section{Who knew what? Sampling for the evaluation}

This research sampled from the two levels (or divisions of expertise) offered by Pawson and Tilley's framework. This included the subjects (or participants) who would, according to Pawson and Tilley (1997) be far more sensitive to the mechanisms and the context and outcome patterns. The second level included the practitioners whose knowledge and experiences would help determine what works (mechanisms) and for who (Contexts).

Purposive sampling offered the most credible option for the evaluation and was employed in this research in terms of its ability to model the population(s) of interest. As Weiss (1998, p. 164) explained:

...purposive sampling is useful in evaluation when the evaluator is interested in data not just on average participants but on participants at the extremes.

The samples for this research were therefore determined according to the two levels of expertise and their respective level of engagement rather than statistical power or size. Thus, expert sampling (O'Hagan et al. 2006) was used to identify programme leads. Using multiple levels of subjects operating at practitioner, participant and programme level (Clarke and Dawson 1999, Coalter 2007, Gray 2014) reflected the 'multiple realities' of complex programmes.

Theory-based evaluations, such as the one conducted in this research, are concerned with determining logical steps between elements of an intervention and its impact on the participating populations (Weiss 1998, Jacobs et al. 2012). The premise of this research was to accrete knowledge through a dialogue with programme implementers or leaders and programme participants. This allowed the evaluation to look within and across the programmes. Hence, a number of phases of data collection were employed, as illustrated in Figure 1. This demonstrates the use of a mixed method design with distinct empirical phases over a 6-year period from 2006 to 2012. The purpose of the preliminary phases was to learn about the programme leaders' explanations of key achievements and potential problems relating to the early phases of the strategy delivery and to inform decisions about the methods used. The second phase provided a detailed understanding of how 


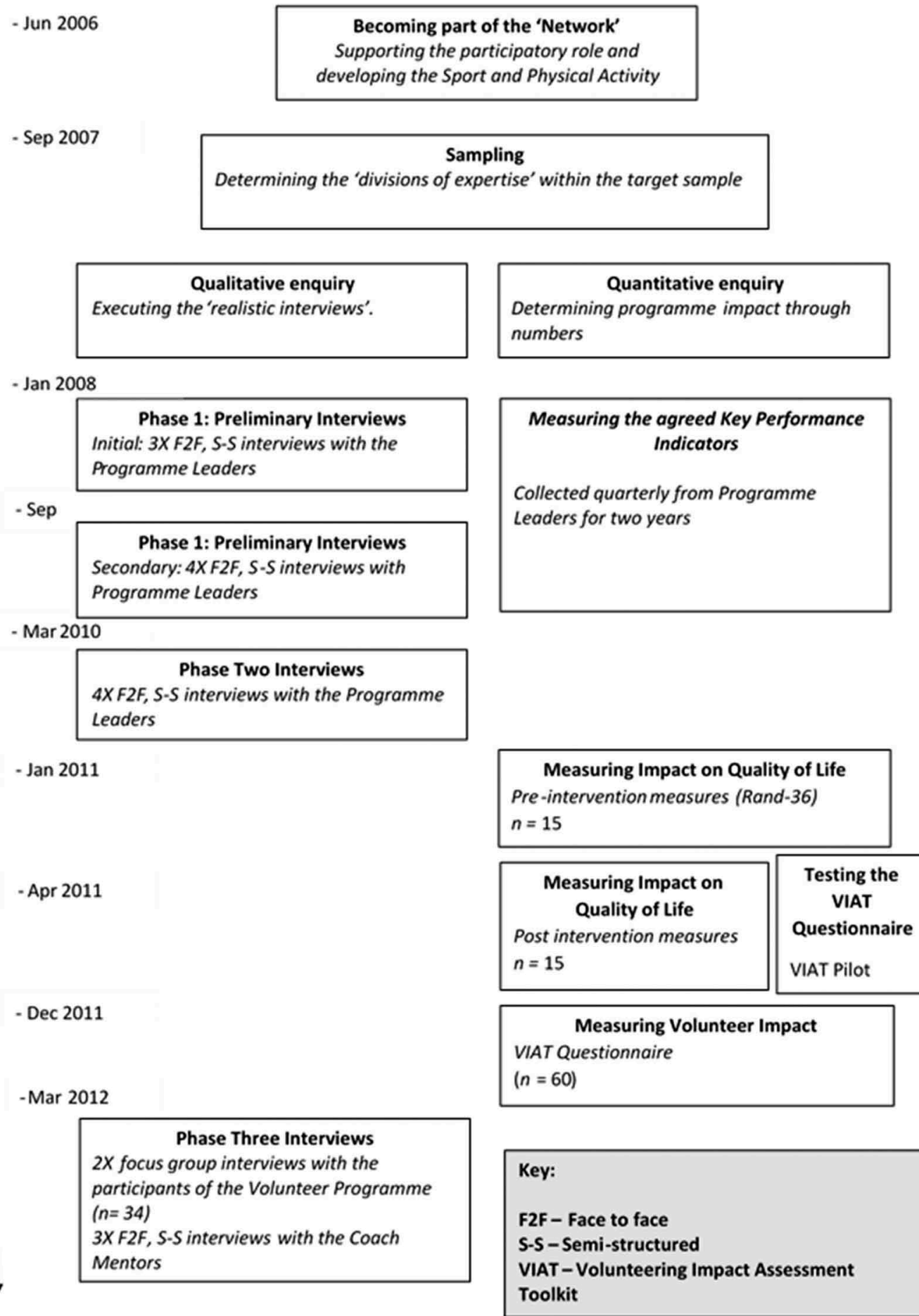

Figure 1. The timeline and activities for the main empirical phases of the research.

the programme changed and developed following initial implementation. The third and final phase explored the extent to which outcomes were realised and importantly, reflect on how they came about. In addition to the series of interviews, a number of questionnaires were utilised with the 
programme participants, each aligned with specific strategy activities and related outcomes. The intention of the questionnaires was not to seek causation but to use 'methods triangulation' (Ammenwerth et al. 2003) to help validate the outcomes recorded in the interviews. Further, there was no intention to generalise the findings of the questionnaire to other similar populations as this study was focussed on the very particular setting of 'this' local community. Rossi et al. (2004) suggested that validity is very dependent on whether the measure is accepted as such by the stakeholders. Stakeholder involvement gave some assurance that it did provide validity for the purpose of the evaluation.

Therefore, this research has enabled insights into not only 'what works' but also 'why it works' and 'for whom' (Pawson and Manzano-Santaella 2012). Rossi et al. (2004) proposed that diversifying measures in this way can safeguard against poorly performing measures that may under-represent outcomes.

Further, in line with the funding body (Sport England 2006b), data were collected quarterly to measure participation against agreed key performance indicators.

\section{Qualitative \& quantitative in the multi-method approach}

The research design relied heavily on qualitative data collected in semi-structured interviews. Gray (2014) explains that using semi-structured interviews, as the name suggests, allows the interviewer to use a standard set of questions. However, they allow for some freedom to probe views where it is desirable and appropriate for respondents to expand on their answers. According to Pawson and Tilley (1997), this is vital when a Realistic Evaluation approach is being undertaken where the objective is to explore levels of reality and the very particular circumstances of those realities. Moreover, a semi-structured interview is well aligned with Bhaskar's (1975) critical realist thinking as probing may allow for the diversion of the interview into new pathways which, while not originally considered will help improve understanding (Gray 2014). The results from the various methods and tools were then subject to in depth analysis across and between programmes to arrive at 'outcome patterns' and CMO configurations, related to key strategic aims, developed in some more depth below.

\section{Making sense of the data}

The interviews were subject to a thematic analysis, as advised by King and Horrocks (2010). Guiding the coding and analysis of the interview transcripts was the broader methodological design. In order to effectively map the coded interviews to the CMO framework, extracts of the interview transcript were colour coded so that any contexts, mechanisms and outcomes could easily be identified at the descriptive level of the coding process. This mapping of codes to the CMO framework was reviewed by the supervisory team to improve the dependability of the data and avoid the interpretational issues such as those identified by RycroftMalone et al. (2010), who suggest that making a distinction between context and mechanism is difficult.

Realistic Evaluation relies heavily on 'generative causes' (Pawson and Tilley 1997, p. 57) to explain programme success. That is, programmes release generative and circumstantial mechanisms through logical reasoning and resource to create change (Nichols 2001). Consequently, the data from the interviews were thematically abducted (Levin-Rozalis 2000). This in contrast to induction which, according to Åsvoll (2014) is used to check pre-determined hypotheses, and deduction, which acts to check theories. There were so many influences and variables in the realities of programme delivery. Consequently, abduction, which acts to draw conclusions from data which can according to Peirce (1955, cited Levin-Rozalis 2000, p. 418) 
...explain facts when there is no basis in previous knowledge that could justify this preference or any checking done after the hypothesis was subject to a trial period.

According to Levin-Rozalis (2000), deductive and inductive logic run contrary to the logic of evaluation research in that evaluation generates hypotheses along the way. Even, as is the case in this research, when the evaluations stems from theory.

The quantitative data analysis relied on pre-determined, non-parametric tests. The analysis helped to strengthen and validate the theories identified in the qualitative chapters in order to 'triangulate the position' of the participants by using '...measures from multiple viewpoints' (Clarke and Dawson 1999, p. 86). Consequently, this research draws on the potential of mixed method to present the multiple realities of delivering a sport and physical activity strategy. In this way, the methodological approach considered mixed method and the CMO configurations because of their capacity to evaluate and offer an improved view of the strategic outcomes. Thus, the mixed method design contributed to developing useful insights into not only 'what worked', but 'why it worked', 'for whom' and 'under what circumstances' (Pawson and Tilley 1997, p. 161). Further, the quantitative data analysis gave the evaluation greater utility to those stakeholders who are accountable to funders requiring 'harder' or more objective indicators of impact or outcome (Grix and Phillpots 2011). This had implications for political issues relating to the diffusion of evidence to inform and develop practice. This is not suggesting that the quantitative data are in any way superior, but more a recognition that sports funding streams are driven by key performance indicators and more objective views of reality.

\section{Outcome patterns for developing health and wellbeing}

Enhancing health and wellbeing has been the bedrock of sports policy for over a decade (DCMS 2002, 2012) and continues to be associated with sport development activity for the future (DCMS 2015). The outcome patterns to explain how improvements in health and wellbeing were facilitated are highlighted in Tables 1-3. Table 1 shows the CMO configuration. It shows that volunteers demonstrated a sense of fulfilment and enjoyment as a marker of wellbeing $(O)$ when taking part in volunteering activity $(\mathrm{M})$ but only if individual needs were met, the staff were highly organised and the activities well timed and conveniently located (C). This sense of fulfilment was explained through increased confidence and competence of volunteers and a sense of belonging. Thus, the interviews indicated, in part, the contribution of the volunteer programme to improved wellbeing but on an emotional or psychological level as opposed to a physical one.

Table 1. Final interview phase CMO configurations for the volunteer programme.

\begin{tabular}{|c|c|c|}
\hline Contexts & Mechanisms & Outcomes \\
\hline $\begin{array}{l}\text { - Varied backgrounds of volunteers in } \\
\text { terms of age, gender, motivation } \\
\text { and readiness }\end{array}$ & $\begin{array}{l}\text { - Using the London } 2012 \text { Olympic Torch Relay events as } \\
\text { an emotive and gratifying hook for volunteering. } \\
\text { - Allowing volunteers to use their individual skills and } \\
\text { perspectives through a review process on enrolling to } \\
\text { the programme } \\
\text { - Giving volunteers responsibility }\end{array}$ & $\begin{array}{l}\text { - Provided safe and } \\
\text { rewarding opportunities for } \\
\text { volunteering } \\
\text { - Increased enthusiasm from } \\
\text { the volunteers to do more } \\
\text { volunteering } \\
\text { - Bringing new skills and } \\
\text { perspectives } \\
\text { - Improved confidence of } \\
\text { volunteers }\end{array}$ \\
\hline $\begin{array}{l}\text { Timing and variety of activity } \\
\text { - Complexities of keeping volunteers } \\
\text { active }\end{array}$ & $\begin{array}{l}\text { - Lag between enrolling on the volunteering } \\
\text { programme and being involved in volunteering } \\
\text { activity }\end{array}$ & $\begin{array}{l}\text { - Demotivating, risk of losing } \\
\text { volunteers }\end{array}$ \\
\hline $\begin{array}{l}\text { - Diverse range of volunteering } \\
\text { activity }\end{array}$ & $\begin{array}{l}\text { - Ensuring more workshops and social events to } \\
\text { encourage 'togetherness' of volunteers. }\end{array}$ & $\begin{array}{l}\text { - Keeping volunteers } \\
\text { motivated and rewarded. }\end{array}$ \\
\hline
\end{tabular}


Table 2. Final interview phase CMO configurations for the coach mentoring programme.

\begin{tabular}{|c|c|c|}
\hline Contexts & Mechanisms & Outcomes \\
\hline $\begin{array}{l}\text { The mentoring process } \\
\text { - Varied interpretations of what } \\
\text { mentoring is and how it may } \\
\text { happen } \\
\text { - Differing styles and } \\
\text { approaches of mentoring. }\end{array}$ & $\begin{array}{l}\text { - Using more than one mentor per mentee } \\
\text { - Empowering the mentee to have a greater degree of } \\
\text { control over mentoring activity and frequency } \\
\text { (informal process). } \\
\text { - An understanding between the Coach Mentor and the } \\
\text { Coach that the mentoring process was mutually } \\
\text { beneficial. } \\
\text { - Participants having financial support }\end{array}$ & $\begin{array}{l}\text { - A more distinct and individual } \\
\text { style of coaching } \\
\text { - Benefit/rewarding for the } \\
\text { mentor as well as the mentee. } \\
\text { Mutual benefits. } \\
\text { - Greater number of better } \\
\text { coaches. }\end{array}$ \\
\hline
\end{tabular}

Table 3. Final interview phase CMO configurations for the disability sports programme.

\begin{tabular}{|c|c|c|}
\hline Contexts & Mechanisms & Outcomes \\
\hline $\begin{array}{l}\text { Participant development and } \\
\text { progression } \\
\text { - Coping with the impact of the } \\
\text { programme on the participants } \\
\text { - Ability and development related to } \\
\text { age } \\
\text { - Coaches' inexperience with } \\
\text { younger age groups } \\
\text { Role and influence of family } \\
\text { - Taking on the family and involving } \\
\text { them in the programme } \\
\text { - Age and levels of disability } \\
\text { important }\end{array}$ & $\begin{array}{l}\text { - Differentiating participant groups based on } \\
\text { ability with (with younger participants) } \\
\text { - One to one coach support with younger age } \\
\text { groups. } \\
\text { - Mini competitions introduced with increased } \\
\text { ability. } \\
\text { - Allowing parents to be involved with the initial } \\
\text { sessions with coach assistance }\end{array}$ & $\begin{array}{l}\text { - Parents enthused by child's sense of } \\
\text { achievement } \\
\text { - Improved parent/sibling } \\
\text { relationship } \\
\text { - Longer term engagement of } \\
\text { children with the programme } \\
\text { - Parents socialise with and support } \\
\text { other parents }\end{array}$ \\
\hline
\end{tabular}

\section{Outcome patterns for enhancing the sporting infrastructure in the coach mentoring programme}

From a strategic perspective, infrastructure was measured through the increased number of coaches and volunteers and further, through sports club involvement. Additionally, infrastructure was explained developmentally through the actions and behaviours of the practitioners and participants of the sports programmes (See Table 2). The interviews explained how coaches were enhancing their practice $(\mathrm{O})$ through a mentoring process $(\mathrm{M})$ and becoming more experienced and skilled $(\mathrm{O})$ in specialist sports coaching roles. This was more apparent when the developing coach was empowered to take charge of their professional development (C).

According to Collins et al. (1999), development of infrastructure was highly dependent on the personalities and motivation of the practitioners (or sport development officers). This was also found in Bell (2004) when looking at the implementation of Champion Coaching programmes. The $\mathrm{CMO}$ configurations were developed from interviews that identified themes of perseverance, capacity to learn and reflect, to compromise and work harmoniously with others. Similarly, Nesti (2008) supported the notion that sport development process was reliant on the characters and personalities of those delivering it. Practitioner traits (part of the context/mechanism interactions) were especially highlighted in the initial interview phases when the implementation of new programmes with new participants and partnerships required the greatest demand on resolve and perseverance. Future strategic groups should consider outcomes related to individual skills and personalities when trying to improve infrastructure more widely. 


\section{Outcome patterns for developing education and skills}

This research demonstrated that a series of sports programmes can positively contribute to the education and skills of those communities it targets. The interviews helped generate logical reasons that explained the mechanisms that would trigger the outcomes. The interviews alone explained that such improvements would only become apparent if there was some mutual and individual benefit from volunteering and if the experience of volunteering was rewarding (C). In this way, confidence improved $(\mathrm{O})$ and the programme would contribute towards education and skill development (O).

The Coach Mentoring programme also contributed to the education and skills of its participants (see Table 2). The interviews acknowledged the higher qualifications of the coaches $(O)$ and the improved confidence and self-efficacy of the coach mentees $(O)$. These outcomes explained through mechanisms suggesting that an informal and pragmatic approach and an 'empowering' process was required. Similarly, the disability sports programmes improved the physical skills of the participants. This was enhanced with the timely interaction of the children's parents and guardians and limiting the class size (M).

\section{Outcome patterns for creating safer and stronger communities}

Finally, perhaps the most profound outcome of the Strategy and its activities was the capacity to bring people together at all levels of programme delivery. Implicit in the disability sport programme was the creation of stronger community for the disabled children. One of the unexpected outcomes of this activity was that the parents became a tight-knit group. This was because of mechanisms that allowed for a timely interaction of the parents with the programme and their children and contextual challenges such as the rapid progress made by the programme participants.

This research also demonstrated that the Volunteer Programme was a vehicle for the development of social capital (cooperative relationships between people). The evidence for this emerged in both the interviews and in the questionnaire which has implications for friendships, contacts and the networks of those involved. In particular, male volunteers and those in the younger age categories were more likely to report improvements in social capital. Once again, for this strategy, such outcomes were only achievable if the contexts, such as the differing volunteer needs were acknowledged and supported by specific programme activities or mechanisms.

Similarly, the Strategy's Coach Mentoring Programme required activity or mechanisms that were sensitive to the differing sports club's needs (context) in order that outcomes patterns such working in partnership with the programme were effective. Further, for both the Volunteer Programme and Coach Mentoring Programme, the relationship had to be seen to be mutually beneficial and in both cases, significant compromise was required of all stakeholders to run the programmes with the creation of safer and stronger communities in mind.

\section{A realistic evaluation: did it work?}

Important to all the reported outcome patterns, noted earlier in this paper, is the recognition that the aims of the strategy were not mutually exclusive. Instead, there is considerable overlap. Methodological plurality combined with pragmatic and logistical considerations enabled using different tools for different programmes dependant on programme size, nature and scope. A Realistic Evaluation is captured by the CMO configuration proposed above. Pawson and Tilley (1997, p. XV) claimed this would '... give us an initial explanatory fix on any social programme'. The challenge in this research was to apply the realistic approach on not one, but several different programmes of a local strategy for sport and physical activity. This application of Realistic Evaluation was set against a backdrop of criticisms that suggest Realistic Evaluation is insufficiently 
operationalised and unable to deal with complex systems (Hansen 2005). More recently, RycroftMalone et al. (2010) found making the distinction between context and mechanism difficult and Barnes et al. (2003) suggested the CMO configuration was unidirectional and unable to capture changes in context because of the programme itself.

In the formative stages of the research, there was significant discussion of process or implementation issues. These issues later led to CMO configurations, which, while process and implementation oriented, provided explanations for short-term, outcome patterns. These outcome patterns were still useful at the strategic level as they helped explain (and contribute to) the progress towards the overarching outcome themes of the strategy. For example, in the preliminary interviews, CMO configurations told of the personalities required of the programme leaders, their perseverance, developing expertise and determination. Such traits were acknowledged in Collins et al. $(1999$, p. 26) report to Department for Culture Media and Sport. The report suggested that '... good projects need an entrepreneur/animatuer/fixer/change maker'. This suggests that early mechanisms were generated by the people implementing the programmes. The attributes of the programme leaders were important contexts or conditions in the implementation stages of the programmes. Such qualities or conditions were required throughout the delivery of the programmes and were arguably contributory to the participants' perceptions that they felt safe and part of a strengthening community as acknowledged later in the interviews with programme participants.

In later CMO configurations, the mechanisms were more closely associated with the activities within the programmes. These mechanisms still relied on the characteristics of those working in sport development. The decisions made within the programme and its activities came from the programme leaders. However, in the latter empirical stages, the participants' perspectives were made at the level of the programme and not those delivering the activities. This is aligned with Pawson and Tilley (1997) notion of generative causation. In current research, programme theory is being developed (or generated) and is understood through the interaction between the programme and the participant (structure and agency). Earlier phases of data gave '...initial explanatory fix[es]' (Pawson and Tilley 1997, p. XV) through the eyes of the programme leaders. Hence, they were the personalised views of administrating and implementing a new programme. Later and supporting the critical realist ontological position that the social world has to be understood at different levels, the participants' view of the programme is given. Consequently, the different generative mechanisms of the programmes emerged due to the interaction between the different levels of involvement with the programme and at distinct stages of programme delivery. Viewed in this way, we learn not only what has happened as a result of the programme but also why the programme had this effect.

Community sports programmes are very rarely delivered in isolation (Perkins and Noam 2007, Robson et al. 2013) and are normally contingent on the efforts of several stakeholders that may represent more than one organisation or group including healthcare specialists, volunteers, facility managers and the participants. It would have been easier to single out a programme and determine its worth. However, this would not be representative of the realities of delivering sport and physical activity to a community. Thus, the ontological position was realised in that a realist school of thinking requires the evaluator to accept that both stakeholders and programmes are rooted in a stratified social reality, independent of the researcher, which results in an interplay between individuals and institutions each with their own objectives and interests (Marchal et al. 2012).

\section{Reflections on the research process}

No research follows a straight line and from its conception to completion, this research was no different. The pragmatic design and idiosyncratic nature of the research setting was a challenge but, in the end, it was the only approach to take if the account of delivering a sport and physical 
activity strategy was to remain 'real'. From sampling and recruiting participants to choosing the tools with which useful information could be gathered for the evaluation, every turn was taken with a degree of uncertainty, helped along by the participatory role taken with the CSN and the research supervisory team.

Clearly, the implementation of new sport development activity was messy and fraught with uncertainty. Houlihan (2005) used the same vernacular in the development of sport policy, as has Coalter (2007). Similarly, those describing the realities of community sport interventions acknowledge the complexities of doing so (Hill 2004, Crabbe 2009, Bell 2010, Trickett et al. 2011), particularly when working with changing circumstances and fluid political situations. Coalter (2007, p. 537) referred to some sport development interventions as '...ill-defined with hard to follow outcomes'. Thus, it is hardly surprising that community sport development evaluation faces many challenges to capture this reality.

If, according to Pawson and Manzano-Santaella (2012, p. 183) current Realistic Evaluation research works by attempting to explain outcomes patterns that '...cannot be determined through anecdotal remarks (on the part of the subjects) then outcomes need to be carefully considered and conceptualised'. The same authors recommend that baselines should be established and '... .before and after measures should be plotted' and complete sets of intervention cohorts be followed. This advice was not followed for all datasets in this research, for a variety of reasons discussed earlier. Further, Clarke and Dawson (1999, p. 55) challenge the '...beforeand-after' design in evaluation; questioning the complexities of ensuring the integrity of such designs throughout the course of an evaluation and challenging its propensity to '...prevent a programme from adapting to changing circumstances'. Such circumstantial change was very apparent in this research. Thus, while the data remained descriptive it is, according to Langbein and Felbinger (2012), still useful at the practitioner level and informed decisions about the future of the programme.

\section{Implications and future research}

Four years have passed since the evaluation of the Sport and Physical Activity Strategy. In this time, participation in sport remains an issue, both locally and Nationally. With further public spending cuts, community sport will have to work harder than ever to survive. Participation will remain a significant issue for local authorities trying to improve health, wellbeing and safer, stronger communities. This research has highlighted important issues that have implications for both community sport development and the research community in terms of addressing an evidence base for community sport.

Firstly, it is evident that sport and physical activity strategy are significant in guiding community sports programmes towards some agreed outcomes and reflect local needs and aspiration. Additionally, the importance of having a small and dedicated, local group responsible for facilitating the delivery of a local sport and physical activity strategy has been highlighted here. Pivotal to bringing about positive changes was the dialogue between the programme leaders and their participants. In this research, the more physical connections these two groups had, the more sustainable the projects became - particularly for volunteering and programmes for disability sport. The evaluation helped encourage this dialogue and gave room for significant reflection on practices. Thus, the research itself may have contributed to some of the Strategy's success in terms of growing and sustaining participation in the programmes. This latter note is certainly worthy of future study. Relatively little has been written about the influence of evaluation itself. This is significant in a service sector such as sport development where successive governments have tasked sport to modernise.

During the time of this research, there was a Labour government who based their concept of modernisation on joined-up, strategic thinking with greater accountability (DCMS 2002); and more recently a Conservative government who decentralised sport and gave greater powers and 
responsibility to citizens. This has added to the complexity of delivery networks for sport which according to Bloyce et al. (2008) could harm rather than harness attempts to achieve government goals and targets for sport. It would be interesting to determine if evaluation has helped or hindered this process.

This research was very reliant on the coming together of an academic institution and a series of local sports development groups. Given the unique features of this evaluation, it would seem prudent to explore, in detail, the nature, power and influence of such groups working together in sport in the context of creating a useable evidence base. The greatest challenge for the design used in this research is its application beyond small community sport development networks. Alongside the practical issues of a realistic framework for evaluation into larger sport development groups are the resource issues. Given the spending cuts already mentioned, future research should primarily look at the feasibility of extending the Realistic Evaluation principles into larger, national and regional environments.

This research gave a wealth of information about the adaptability and survivability of sport development teams and programmes. This interplay between programmes and people in community sport deserves more attention than this evaluation could give it. However, to better understand relationships with this practice further socio-psychological perspectives may illuminate the varied interpretation and realities of community sport at the level of delivery. This would provide important theories to test in future Realistic Evaluations.

Finally, the political value and impact of this research needs to be acknowledged. If the purpose of evaluation is to improve, and the ways in which improvement is sought are both varied and multifaceted, it is in the best interest of evaluation researchers to consider how well accepted the evidence they produce will be. During the research period, the funders and policy makers challenged sport development to find a way to better evaluate its work. Given the economic threats and the probable policy shifts over the coming decade, sport will have to survive by developing '... a better mechanism for an improved evidence base' (DCMS 2008, p. 16). If, as Cameron (2009) alluded to, our sport development citizens are now in control of local sport development activity, then there needs to be further explorations of the sector's capacity to conduct useful evaluations. Additionally, this would require a dialogue with higher echelons of policy making and funding to resource evaluation and accept the varied forms in which evidence can present itself. This will be a difficult task and an enormous challenge when outside the remit of more centralised government department activity and in a time of economic uncertainty.

\section{Disclosure statement}

No potential conflict of interest was reported by the authors.

\section{Notes on contributors}

John E Daniels is a Principal Lecturer for the Department of Sport and Exercise Sciences at Manchester Metropolitan University. His interests are in community interventions that seek to increase physical activity and participation in sport.

Barbara Bell is Senior Lecturer in Sport Development at Manchester Metropolitan University, in the Department of Sport and Exercise Sciences, with research interests in the impacts of London 2012 on school, club and community sport, the development of sport for women, specifically women's football, social marketing and the promotion of sport participation and programme evaluations in sport development. Barbara teaches at Undergraduate and Post Graduate levels in sport development and has published in a number of journals and edited collections across her research interests

Christine Horrocks is Pro-Vice Chancellor of Manchester Metropolitan University's Cheshire Campus. As Professor of Applied Social Psychology Christine has worked with a range of agencies completing funded research projects investigating a series of policy interventions focussing on understanding health related behaviour and behaviour change. Her research includes collaboration with the probation service investigating coercive treatment interventions for drug and alcohol misuse. 


\section{References}

Adams, A. and Harris, K., 2014. Making sense of the lack of evidence discourse, power and knowledge in the field of sport for development. International journal of public sector management, 27 (2), 140-151. doi:10.1108/IJPSM-062013-0082

Ammenwerth, E., Iller, C., and Mansmann, U., 2003. Can evaluation studies benefit from triangulation? A case study. International journal of medical informatics, 70 (2), 237-248.

Åsvoll, H., 2014. Abduction, deduction and induction: can these concepts be used for an understanding of methodological processes in interpretative case studies? International journal of qualitative studies in education, 27 (3), 289-307. doi:10.1080/09518398.2012.759296

Audit Commission., 2002. Sport and recreation: learning from audit, inspection and research. London: Audit Commission.

Barnes, M., Matka, E., and Sullivan, H., 2003. Evidence, understanding and complexity evaluation in non-linear systems. Evaluation, 93, 265-284. doi:10.1177/13563890030093003

Bean, C.N., et al., 2015. Putting program evaluation into practice: enhancing the girls just wanna have fun program. Evaluation and program planning, 49, 31-40. doi:10.1016/j.evalprogplan.2014.11.007

Bell, B., 2004. An evaluation of the impacts of the Champion Coaching Scheme on youth sport and coaching. Thesis (PhD). Loughborough University. Loughborough.

Bell, B., 2010. Legacy evidence and evaluation: the elusive nature of sport development legacy. PSA/POLSIS conference, 11 July 2010 Birmingham: University of Birmingham.

Bhaskar, R., 1975. Forms of realism. Philosophica online, 15 (1), 99-127. Available from: https://philpapers.org/rec/ BHAFOR

Bloyce, D., et al., 2008. 'Playing the game (plan)': a figurational analysis of organizational change in sports development in England. European sport management quarterly, 8 (4), 359-378. doi:10.1080/16184740802461637

Cameron, D., 2009. Hugo young lecture: the big society. London: Kings Place. 10th November 2009.

Chen, S. and Henry, I., 2016. Evaluating the London 2012 games' impact on sport participation in a non-hosting region: a practical application of realist evaluation. Leisure studies, 35 (5), 685-707. doi:10.1080/ 02614367.2015 .1040827

Clarke, A. and Dawson, R., 1999. Evaluation research: an introduction to principles, methods and practice. London: Sage.

Coalter, F., 2007. A wider social role for sport: who's keeping the score? London: Routledge.

Coalter, F., 2013. Sport for development: what game are we playing? London: Routledge.

Coalter, F., 2017. Sport and social inclusion: evidence-based policy and practice. Social inclusion, 5 (2), $141-149$. doi:10.17645/si.v5i2.852

Collins, M., et al., 1999. Sport and social inclusion: a report to the department of culture media and sport. Loughborough: Loughborough University.

Collins, M.F. and Kay, T., 2003. Sport and social exclusion. London: Routledge.

Crabbe, T., 2009. Getting to know you: using sport to engage and build relationships with socially marginalised young people. In: R. Levermore and A. Beacom, eds. Sport and international development. Basingstoke: Palgrave, $176-197$.

Davies, L.E., 2016. A wider role for sport: community sports hubs and urban regeneration. Sport in society, 19 (10), 1537-1555. doi:10.1080/17430437.2016.1159192

Davies, P., 2000. Approaches to evidence-based teaching. Medical teacher, 22 (1), 14-21. doi:10.1080/01421590078751

Department for Culture Media and Sport., 2002. Game plan: a strategy for the government's sport and physical activity objectives. London: Strategy Unit.

Department for Culture Media and Sport., 2008. A passion for excellence: an improvement strategy for culture and sport. London: LGA.

Department for Culture, Media and Sport., 2012. Creating a sporting habit for life. London: DCMS.

Department for Digital Culture Media and Sport., 2015. Sporting future: a new strategy for an active nation. London: DCMS.

Frisby, W., Thibault, L., and Kikulis, L., 2004. The organizational dynamics of under-managed partnerships in leisure service departments. Leisure studies, 23 (2), 109-126. doi:10.1080/0261436042000224482

Gray, D.E., 2014. Doing research in the real world. London: Sage.

Green, M. and Houlihan, B., 2004. Advocacy coalitions and elite sport policy change in Canada and the United Kingdom. International review for the sociology of sport, 39 (4), 387-403. doi:10.1177/1012690204049066

Grix, J. and Carmichael, F., 2012. Why do governments invest in elite sport? A polemic. International journal of sport policy and politics, 4 (1), 73-90. doi:10.1080/19406940.2011.627358

Grix, J. and Phillpots, L., 2011. Revisiting the 'governance narrative' 'asymmetrical network governance' and the deviant case of the sports policy sector. Public policy and administration, 26 (1), 3-19. doi:10.1177/ 0952076710365423

Hansen, H.F., 2005. Choosing evaluation models: a discussion on evaluation design. Evaluation, 11 (4), $447-462$. doi: $10.1177 / 1356389005060265$

Harris, K., 2018. Building sport for development practitioners' capacity for undertaking monitoring and evaluationreflections on a training programme building capacity in realist evaluation. International journal of sport policy and politics, 1-20. doi:10.1080/19406940.2018.1442870 
Harris, K. and Adams, A., 2016. Power and discourse in the politics of evidence in sport for development. Sport management review, 19 (2), 97-106. doi:10.1016/j.smr.2015.05.001

Hart, D., Diercks-O'Brien, G., and Powell, A., 2009. Exploring stakeholder engagement in impact evaluation planning in educational development work. Evaluation, 15 (3), 285-306. doi:10.1177/1356389009105882

Hill, D., 2004. Evaluation of community-level interventions for health improvement: a review of experience in the UK. London: Health Development Agency.

Houlihan, B., 2005. Public sector sport policy developing a framework for analysis. International review for the sociology of sport, 40 (2), 163-185. doi:10.1177/1012690205057193

Houlihan, B. and White, A., 2002. The politics of sports development: development of sport or development through sport? London: Routledge.

Hylton, K. and Bramham, P., eds., 2008. Sports development: policy, process and practice. Abingdon: Taylor \& Francis.

Jacobs, W.J., et al., 2012. Evaluating theory-based evaluation: information, norms, and adherence. Evaluation and program planning, 35 (3), 354-369. doi:10.1016/j.evalprogplan.2011.12.002

King, N. and Horrocks, C, 2010. Interviews in qualitative research. London: Sage.

Krustrup, P., Dvorak, J., and Bangsbo, J., 2016. Small-sided football in schools and leisure-time sport clubs improves physical fitness, health profile, well-being and learning in children. British journal of sports medicine online, 50, 11661167. Available from: http://www.tandf.co.uk/journals/authors/style/reference/tf_X.pdf. [Accessed 21 May 2017 ].

Langbein, L.I. and Felbinger, C., 2012. Public program evaluation: a statistical guide. London: Routledge.

Levin-Rozalis, M., 2000. Abduction: a logical criterion for programme and project evaluation. Evaluation, 6 (4), 415-432. doi:10.1177/13563890022209406

Marchal, B., et al., 2012. Is realist evaluation keeping its promise? A review of published empirical studies in the field of health systems research. Evaluation, 18 (2), 192-212. doi:10.1177/1356389012442444

Mercier, C., 1997. Participation in stakeholder-based evaluation: a case study. Evaluation and program planning, 20 (4), 467-475. doi:10.1016/S0149-7189(97)00026-8

Ministry of Housing Communities and Local Government, 2015. English indices of deprivation 2015 [online]. London: Ministry of Housing Communities and Local Government. Available from: https://www.gov.uk/government/statis tics/english-indices-of-deprivation-2015

Nesti, M., 2008. Challenging yourself to challenge others [online]. Available from: http://www.theleisurereview.co.uk/ articles08/nesti.html

Nichols, G., 2001. A realist approach to evaluating the impact of sports programmes on crime reduction. In: G. McPherson and G. Reid, eds. Leisure and social inclusion: new challenges for policy and provision (LSA publication no.73). Eastbourne: LSA, 71-80.

Nichols, G., 2005. Reflections on researching the ability of sports interventions to reduce youth crime: the hope of scientific realism. In: K. Hylton, J. Long, and A. Flintoff, eds. Evaluating sport and active leisure for young people. Eastbourne: Leisure Studies Association, 23-44.

O'Hagan, A., et al., 2006. Uncertain judgements: eliciting experts' probabilities. Chichester: John Wiley \& Sons.

O'Sullivan, R.G. and D'Agostino, A., 2002. Promoting evaluation through collaboration. Evaluation, 8 (3), $372-387$. doi:10.1177/135638902401462466

Office for National Statistics, 2011. 2011 Census online. London: Office for National Statistics. Available from: https:// www.ons.gov.uk/census/2011census

Pawson, R. and Manzano-Santaella, A., 2012. A realist diagnostic workshop. Evaluation, 18 (2), 176-191. doi:10.1177/ 1356389012440912

Pawson, R. and Tilley, N., 1997. Realistic evaluation. London: Sage.

Perkins, D.F. and Noam, G.G., 2007. Characteristics of sports-based youth development programs. New directions for youth development, 115, 75-84. doi:10.1002/yd.224

Reddy, P., et al., 2017. Walking football as sustainable exercise for older adults - a pilot investigation. European journal of sport science, 17 (5), 638-645. doi:10.1080/17461391.2017.1298671

Robson, S., Simpson, K., and Tucker, L., 2013. Strategic sport development. London: Routledge.

Rossi, P.H., Lipsey, M.W., and Freeman, H.E., 2004. Evaluation: a systematic approach, 7th. London: Sage Publications.

Rycroft-Malone, J., et al., 2010. A realistic evaluation: the case of protocol-based care. Implementation science online, 5, Available from: https://implementationscience.biomedcentral.com/articles/10.1186/1748-5908-5-38 [Accessed on 10 May 2017].

Sixsmith, J. and Daniels, J., 2011. Action research. In: P. Banister, ed.. Qualitative methods in psychology: a research guide. Maidenhead: McGraw-Hill International, 22-37.

Sport England, 2006a. Active people survey online. London: Sport England. Available from: http://www.sportengland. org/research/active_people_survey.aspx

Sport England, 2006b. About the community investment fund online. London: Sport England. Available from: http:// webarchive.nationalarchives.gov.uk/20080609152647/http://www.sportengland.org/text/index/get_funding/how_ funding_works/about_the_community_investment_fund.htm

Trickett, E.J., Espino, S.R., and Hawe, P., 2011. How are community interventions conceptualized and conducted? An analysis of published accounts. Journal of community psychology, 39 (5), 576-591. doi:10.1002/jcop.20455 
Weed, M., 2016. Should we privilege sport for health? The comparative effectiveness of UK government investment in sport as a public health intervention. International journal of sport policy and politics, 8 (4), 559-576. doi:10.1080/ 19406940.2016.1235600

Weiss, C.H., 1972. Evaluation research. New Jersey: Prentice-Hall.

Weiss, C.H., 1998. Evaluation: methods for studying programs and policies. New Jersey: Prentice Hall.

Widdop, P., et al., 2017. Austerity, policy and sport participation in England. International journal of sport policy and politics, $10(1), 7-24 .$. 